\title{
Endometrial Cancer Diagnosed by the Presence of Bone Metastasis and Treated with Zoledronic Acid: A Case Report and Review of the Literature
}

\author{
Aiko Shigemitsu Naoto Furukawa Natsuki Koike \\ Hiroshi Kobayashi \\ Department of Obstetrics and Gynecology, Nara Medical University, \\ Kashihara, Japan
}

\section{Key Words}

Bisphosphonates · Bone metastasis · Endometrial cancer

\begin{abstract}
Bone metastasis from endometrial cancer is rare. We report a case of endometrial cancer which was diagnosed by the presence of bone metastasis and treated with zoledronic acid. A 57-year-old woman complaining of progressive right hip pain consulted an orthopedist. She had no gynecologic complaints. X-rays revealed an osteolytic lesion of the right ischium. Bone scintigraphy was subsequently carried out and showed isotope accumulation in the right ischium. Computed tomography revealed an enlarged uterus; the patient consequently consulted a gynecologist. Histological sections of an endometrial biopsy showed endometrioid adenocarcinoma. Hysterectomy and bilateral salpingo-oophorectomy, as well as bone biopsy of the right ischium, were therefore carried out. A moderately differentiated endometrioid adenocarcinoma was expressed in the corpus. Histopathological examination of the bone biopsy also revealed adenocarcinoma. The final diagnosis was stage IVB endometrial cancer with bone and lung metastasis. Good pain relief was achieved due to chemotherapy. However, 2 months after completion of the chemotherapy, the patient was administered zoledronic acid because her hip pain had gradually increased. Following zoledronic acid administration, the hip pain reduced. Radiotherapy was then given for the right ischial metastasis after the ninth course of zoledronic acid therapy because the metastasis site had increased and the possibility of a pathological fracture had risen. However, the patient died 21 months after the initial treatment because of disease progression.
\end{abstract}




\begin{tabular}{|c|c|c|c|}
\hline $\begin{array}{c}\text { Case Reports in } \\
\text { Oncoloys }\end{array}$ & \begin{tabular}{|l|} 
Case Rep Oncol 2010;3:471-476 \\
DOI: $10.1159 / 000323150$
\end{tabular} & $\begin{array}{l}\text { Published online: } \\
\text { December } 13,2010\end{array}$ & $\begin{array}{l}\text { O 2010 S. Karger AG, Basel } \\
\text { ISSN 1662-6575 } \\
\text { www.karger.com/cro }\end{array}$ \\
\hline
\end{tabular}

\section{Introduction}

Endometrial cancer is the most common malignancy of the female genital tract, and its incidence has increased remarkably. In Japan, the total number of endometrial cancer cases increased from 2,115 in 1994 to 4,267 in 2005 [1]. The first presenting symptom is commonly vaginal bleeding and most patients are at an early stage [2], resulting in a favorable overall survival rate. Endometrial cancer is more likely to metastasize to the lymph nodes, liver and lungs, while bone metastasis is very rare. Radiotherapy has been proven to play a palliative role in patients with bone metastases and administration of bisphosphonates, especially zoledronic acid, is used to prevent the symptoms of bone metastasis.

We report a case of endometrial cancer which was diagnosed by the presence of bone metastasis and treated with zoledronic acid, and review the related literature.

\section{Case Report}

A 57-year-old Japanese woman consulted an orthopedist, complaining of progressive right hip pain over a period of 2 months and lower abdominal pain. She had no gynecologic complaints such as vaginal bleeding. She was gravida 3, para 3, and menstruation had ceased at 44 years of age. Her medical history indicated that she had undergone a total gastrectomy, followed by chemotherapy, for treatment of gastric cancer 4 years previously. X-rays revealed an osteolytic lesion on the right ischium. Bone scintigraphy was carried out and showed isotope (technetium TC99m) accumulation in the right ischium and right pubis. These findings suggested that the lesion was likely to be a bone metastasis of the gastric cancer. However, computed tomography revealed an enlarged uterus with swelling of the para-aortic nodes and multiple lung nodes, which prompted a gynecologic consultation. Consequently, she was referred to our hospital for a gynecologic examination. Magnetic resonance imaging showed enlargement of the uterus, with a mass measuring $3 \times 4 \mathrm{~cm}$ in the endometrial cavity. The mass showed heterogeneous medium and high signal intensity on T2-weighted images, and swelling of the left ovary was observed. An endometrial biopsy was performed and subjected to histological examination. Hematoxylin and eosin-stained sections showed a well-differentiated endometrioid adenocarcinoma. She was therefore diagnosed with endometrial cancer.

A hysterectomy, bilateral salpingo-oophorectomy and bone biopsy of the right ischium were carried out. Peritoneal cytology was negative. On pathological examination, a moderately differentiated endometrioid adenocarcinoma was expressed in the corpus and cervix of the uterus and left ovary. Histopathological examination of the bone biopsy revealed an adenocarcinoma that was $\mathrm{CK} 7^{+} / \mathrm{CK} 20^{-}$ and $\mathrm{ER}^{+} / \mathrm{PR}^{+}$. The final diagnosis was stage IVB endometrial cancer with bone and lung metastases. The postoperative treatment consisted of paclitaxel $\left(180 \mathrm{mg} / \mathrm{m}^{2}\right)$ plus carboplatin $(\mathrm{AUC}=6)$ for 6 cycles, because of the multiple metastases. As a result, good pain relief was achieved and the other metastases became smaller. However, 2 months after completion of the chemotherapy, the hip pain gradually increased, and she was administered zoledronic acid for symptom relief of the bone metastasis. After receiving zoledronic acid, her hip pain gradually reduced. Radiotherapy was given for the right ischial metastasis ( $37.5 \mathrm{~Gy} / 15 \mathrm{Fr}$ ) after the ninth course of zoledronic acid therapy because the metastasis site had increased and the possibility of a pathological fracture had risen. However, the patient died 21 months after the initial treatment because of disease progression.

\section{Discussion}

Bone metastases are the most common malignant bone tumors, and their most common primary tumors are lung and breast cancers. Bone metastasis is rare in endometrial cancer, with a reported frequency of $0-8 \%[3,4]$. In an autopsy study, the corresponding frequency was $25-27 \%[5,6]$ and the vertebrae were the most common 


\begin{tabular}{c|l|l|l}
$\begin{array}{c}\text { Case Reports in } \\
\text { Olloloyy }\end{array}$ & $\begin{array}{l}\text { Case Rep Oncol 2010;3:471-476 } \\
\text { DOI: 10.1159/000323150 }\end{array}$ & $\begin{array}{l}\text { Published online: } \\
\text { December 13, 2010 }\end{array}$ & $\begin{array}{l}\text { ISSN 1662-6575 } \\
\text { www.karger.com/cro }\end{array}$ \\
\hline
\end{tabular}

metastasis sites [5]. Bone metastasis is usually seen together with intra-abdominal and pelvic recurrences and/or other organ metastases. It is assumed that the mechanism of the vertebral metastasis involves Batson's paravertebral valveless venous plexus [7]. It is also possible that the vascular invasion could start in the lymphatics, where tumor cells gain access to the venous return and then to the systemic circulation via arterial outflow $[8,9]$.

The reported cases in the English literature obtained in searches of the PubMed and ScienceDirect electronic databases up to June 2010 are presented in table 1 and table 2. Table 1 shows the diagnostic cases of bone metastasis after initial treatment of endometrial cancer. In the 31 cases, the average interval between the detection of the endometrial cancer and the bone metastasis varied from 1 to 148 months (median, 17 months). A high incidence of bone metastasis with high-grade adenocarcinoma was revealed. All the patients complained of pain at the bone metastatic site, and the limbs and vertebrae were more frequently involved than the pelvis. Radiotherapy was frequently selected in the treatment of bone metastasis, and 18 patients died between 1 and 54 months (median, 8.5 months) after detection of the bone metastasis. Table 2 shows cases in which the bone metastasis was simultaneously detected at the time of the diagnosis of endometrial cancer. In those 21 cases, the most common first presenting symptom was pain and only 2 had vaginal bleeding. A high incidence of bone metastasis with highgrade adenocarcinoma was revealed, and showed the same pattern as the recurrence cases. Although the limbs were the most frequent metastatic sites, pelvic metastasis was more frequently observed in the initial diagnosis cases (33\%) than in the recurrence cases (13\%). This situation is considered to arise because the uterine tumors had stayed in the pelvis for a long time in the initial diagnosis cases. Radiotherapy was often selected in the treatment of bone metastasis. Ten patients died between 2 and 34 months (median, 9.5 months) after diagnosis. Although the first presenting symptom is usually vaginal bleeding and most patients are at an early stage of endometrial cancer, the first presenting symptom in these cases was hip pain, not vaginal bleeding. Therefore, there might have been a delay before the patients consulted a physician at the hospital.

In the present case, chemotherapy was chosen first because there were multiple distant metastases as well as the bone metastasis. As a result, the hip pain and tumor size were temporarily reduced. However, 2 months after completion of the chemotherapy, the hip pain had increased. The patient refused to receive further chemotherapy or hormone therapy. It has been reported that zoledronic acid may be effective for not only bone metastasis but also soft tissue organ metastases [10]. Therefore, only zoledronic acid was administered for pain relief. This case is the first report of administration of zoledronic acid for bone metastasis of endometrial cancer. Zoledronic acid was effective for the hip pain but could not suppress the growth of the bone metastasis. In this case, radiotherapy was not used concomitantly with zoledronic acid because of the multiple metastases. However, it has been reported that bisphosphonates seem to improve the clinical results obtained with radiotherapy in bone metastasis of renal cell carcinoma [11]. In our review, the median prognosis was 8-9 months' survival time after diagnosis of bone metastasis. Our patient survived for 21 months after detection of the bone metastasis, and zoledronic acid as well as chemotherapy and radiotherapy might have contributed to this outcome.

In conclusion, the present case involved bone metastasis from endometrial cancer, which is rare. Vaginal bleeding as the first symptom was absent, and consequently the disease was not detected until it had progressed to bone metastasis. In addition, this 
report describes the use of zoledronic acid for bone metastasis of endometrial cancer for the first time.

Table 1. The diagnostic cases of bone metastasis after initial treatment of endometrial cancer $(\mathrm{n}=31)$

\begin{tabular}{|c|c|c|c|c|c|c|c|c|c|c|}
\hline Case & $\begin{array}{l}\text { Age } \\
\text { years }\end{array}$ & $\begin{array}{l}\text { Time to } \\
\text { bone } \\
\text { metas- } \\
\text { tasis } \\
\text { months }\end{array}$ & $\begin{array}{l}\text { Histo- } \\
\text { logy }\end{array}$ & Stage & $\begin{array}{l}\text { Site(s) of bone } \\
\text { metastasis }\end{array}$ & $\begin{array}{l}\text { Other } \\
\text { site(s) of } \\
\text { metastasis }\end{array}$ & Symptom(s) & Treatment & $\begin{array}{l}\text { Survival } \\
\text { after } \\
\text { bone } \\
\text { metastasis } \\
\text { months }\end{array}$ & $\begin{array}{l}\text { Dead } \\
\text { or } \\
\text { alive }\end{array}$ \\
\hline 1 & 67 & 15 & adeno & I & fibula & & pain & RT & 12 & dead \\
\hline 2 & 59 & 9 & G2 & $\mathrm{IC}$ & femur & lung & pain, swelling & RT, chemo, HRT & & \\
\hline 3 & 48 & 30 & G2-G3 & IIB & femur & lung & pain & RT, chemo, HRT & 41 & alive \\
\hline 4 & 77 & 24 & G3 & IC & metatarsus & lung & pain & amputation, RT, HRT & 16 & alive \\
\hline 5 & 86 & 18 & SCC & IIIC & hallux & lung & pain & amputation & & dead \\
\hline 6 & 67 & 4 & & IC & $\begin{array}{l}\text { tibia, femur, } \\
\text { metatarsus }\end{array}$ & & pain & RT & 2 & dead \\
\hline 7 & 66 & 18 & G3 & IA & humerus & & pain & RT, HRT & 24 & alive \\
\hline 8 & 45 & 36 & G2 & IA & cranium & lung & swelling & surgery, RT & 6 & dead \\
\hline 9 & 55 & 18 & adeno & & calcaneus, talus & lung & pain & RT & 36 & alive \\
\hline 10 & 55 & 24 & G2 & IB & calcaneus & & pain & RT & 10 & alive \\
\hline 11 & 87 & 108 & & & sternum & & pain & surgery & 60 & alive \\
\hline 12 & 67 & 60 & adeno & IVB & mandibula & lung, kidney & pain, swelling & surgery & & dead \\
\hline 13 & 51 & 1 & G3 & IIIC & humerus & lymph node & pain & RT & 6 & alive \\
\hline 14 & 61 & & G1 & IIIB & calcaneus & & pain & & & \\
\hline 15 & 81 & 36 & adeno & IIB & calcaneus & & pain & RT & & \\
\hline 16 & 70 & 24 & G3 & IC & ischium & & pain & chemo, pamidronate & 36 & alive \\
\hline 17 & 61 & 44 & G1 & IIIA & vertebrae & any & pain & RT, surgery & 12 & dead \\
\hline 18 & 65 & 3 & adeno & IIIB & vertebrae, rib & any & pain & chemo & 9 & dead \\
\hline 19 & 58 & 10 & adeno & IA & L4, L5 & & pain & RT, surgery, chemo & 199 & alive \\
\hline 20 & 70 & 10 & G3 & IIB & vertebrae, rib, parietal & any & pain & RT & 2 & dead \\
\hline 21 & 65 & 7 & G1 & IIIB & tibia, femur & any & pain & RT, surgery & 42 & dead \\
\hline 22 & 55 & 25 & adeno & & pelvis, vertebrae, rib & any & pain & chemo & 7 & dead \\
\hline 23 & 60 & 12 & clear & & humerus, clavicle & & pain & surgery, RT, chemo & 13 & dead \\
\hline 24 & 71 & 16 & G2 & IVB & L1, L3, L4 & any & pain & & 1 & dead \\
\hline 25 & 74 & 8 & adeno & IB & vertebrae, rib & any & pain & RT, chemo & 5 & dead \\
\hline 26 & 62 & 11 & G2 & IIIC & $\begin{array}{l}\text { calvarium, femur, } \\
\text { spine }\end{array}$ & any & pain & surgery & 54 & dead \\
\hline 27 & 60 & 3 & G3 & IVB & sacroiliac joint & any & pain & RT, chemo & 8 & dead \\
\hline 28 & 52 & 148 & & & vertebrae & any & pain & surgery & 7 & dead \\
\hline 29 & 55 & 9 & G3 & IIIC & rib, femur, spine & & pain & RT, surgery & 26 & dead \\
\hline 30 & 40 & 3 & G3 & IIIC & ischium & & pain & chemo & 10 & dead \\
\hline 31 & 56 & 26 & G2 & IC & femur & any & pain & surgery, chemo & 12 & alive \\
\hline
\end{tabular}

adeno = Adenocarcinoma; SSC = squamous cell carcinoma; RT = radiotherapy; HRT = hormone replacement therapy; chemo = chemotherapy. 
Table 2. Cases of bone metastasis detected simultaneous with diagnosis of endometrial cancer $(\mathrm{n}=21)$

\begin{tabular}{|c|c|c|c|c|c|c|c|c|}
\hline Case & $\begin{array}{l}\text { Age } \\
\text { years }\end{array}$ & Histology & Site(s) of bone metastasis & $\begin{array}{l}\text { Other site(s) of } \\
\text { metastasis }\end{array}$ & Symptom(s) & Treatment & $\begin{array}{l}\text { Survival after } \\
\text { bone metastasis } \\
\text { months }\end{array}$ & $\begin{array}{l}\text { Dead or } \\
\text { alive }\end{array}$ \\
\hline 2 & 61 & G1 & calcaneus, talus & & pain, swelling & surgery, chemo, HRT & 14 & alive \\
\hline 3 & & G1 & ischium & & pain & RT & 48 & alive \\
\hline 6 & 59 & G2 & calcaneus & & pain & RT, chemo, HRT & 60 & alive \\
\hline 7 & 73 & G3 & tibia & & pain & chemo & 9 & dead \\
\hline 8 & 51 & G3 & cervical vertebra & & bleeding & chemo & 2 & dead \\
\hline 9 & 70 & G1 & tibia & & pain & RT, chemo & 47 & alive \\
\hline 10 & 64 & CS & tibia & & pain & RT & 6 & dead \\
\hline 14 & 57 & & tibia & lung, kidney & & RT & & \\
\hline 15 & 67 & G1 & calcaneus, talus, metatarsal & & pain & surgery & 20 & alive \\
\hline 16 & 55 & G3 & ischium, acetabulum, femur & & pain & RT, surgery & 10 & dead \\
\hline 17 & 47 & G2 & $\begin{array}{l}\text { vertebrae, acetabulum, femur, } \\
\text { humerus }\end{array}$ & & pain & chemo & 7 & dead \\
\hline 18 & 62 & G3 & vertebrae & any & pain & RT, chemo & 16 & dead \\
\hline 19 & 32 & G3 & pubic rami, acetabulum & & pain & RT, chemo & 5 & alive \\
\hline 20 & 84 & G2 & $\begin{array}{l}\text { ischium, superior ramus, } \\
\text { acetabulum }\end{array}$ & & pain & $\mathrm{RT}$ & 34 & dead \\
\hline 21 & 77 & G3 & $\begin{array}{l}\text { inferior pubic ramus, sacrum, } \\
\text { acetabulum }\end{array}$ & any & pain & RT, chemo & 8 & dead \\
\hline
\end{tabular}

adeno $=$ Adenocarcinoma $\mathrm{RT}=$ radiotherapy $\mathrm{HRT}=$ hormone replacement therapy; chemo = chemotherapy . 


\begin{tabular}{|c|c|c|c|}
\hline $\begin{array}{c}\text { Case Reports in } \\
\text { Oncoloy }\end{array}$ & \begin{tabular}{|l|} 
Case Rep Oncol 2010;3:471-476 \\
DOI: $10.1159 / 000323150$
\end{tabular} & $\begin{array}{l}\text { Published online: } \\
\text { December 13, } 2010\end{array}$ & $\begin{array}{l}\text { ( ) } 2010 \text { S. Karger AG, Basel } \\
\text { ISSN } 1662-6575 \\
\text { www.karger.com/cro }\end{array}$ \\
\hline
\end{tabular}

\section{References}

1 Ushijima K: Current status of gynecologic cancer in Japan. J Gynecol Oncol 2009;20:67-71.

2 Wolfson AH, Sightler SE, Markoe AM, Schwade JG, Averette HE, Ganjei P, Hilsenbeck SG: The prognostic significance of surgical staging for carcinoma of the endometrium. Gynecol Oncol 1992;45:142-146.

-3 Kaya A, Olmezoglu A, Eren CS, Bayol U, Altay T, Karapinar L, Ozturk H, Oztekin D, Guvenli Y, Karadogan I: Solitary bone metastasis in the tibia as a presenting sign of endometrial adenocarcinoma: a case report and the review of the literature. Clin Exp Metastasis 2007;24:87-92.

-4 Neto AG, Gupta D, Broaddus R, Malpica A: Endometrial endometrioid adenocarcinoma in a premenopausal woman presenting with metastasis to bone: a case report and review of the literature. Int J Gynecol Pathol 2002;21:281-284.

5 Abdul-Karim FW, Kida M, Wentz WB, Carter JR, Sorensen K, Macfee M, Zika J, Makley JT: Bone metastasis from gynecologic carcinomas: a clinicopathologic study. Gynecol Oncol 1990;39:108-114.

6 Abrams HL, Spiro R, Goldstein N: Metastases in carcinoma: analysis of 1,000 autopsied cases. Cancer 1950;3:74-85.

7 Batson OV: The function of the vertebral veins and their role in the spread of metastases. Ann Surg 1940;112:138-149.

8 Amiot RA, Wilson SE, Reznicek MJ, Webb BS: Endometrial carcinoma metastasis to the distal phalanx of the hallux: a case report. J Foot Ankle Surg 2005;44:462-465.

\9 Cooper JK, Wong FL, Swenerton KD: Endometrial adenocarcinoma presenting as an isolated calcaneal metastasis. A rare entity with good prognosis. Cancer 1994;73:2779-2781.

10 Croucher P, Jagdev S, Coleman R: The anti-tumor potential of zoledronic acid. Breast 2003;12(suppl 2):S30S36.

11 Kijima T, Fujii Y, Suyama T, Okubo Y, Yamamoto S, Masuda H, Yonese J, Fukui I: Radiotherapy to bone metastases from renal cell carcinoma with or without zoledronate. BJU Int 2009;103:620-624. 